\title{
High performance masonry wall systems: principles derived from natural analogues
}

\author{
J. Laver, D. Clifford \& J. Vollen \\ Emerging Material Technologies, \\ University of Arizona, United States of America
}

\begin{abstract}
Flora and fauna have developed strategies to flourish in response to the climatic conditions of a specific place. These strategies are reexamined as a masonry wall system in response to local environment. Two natural systems are studied as models for architectural propositions that mimic nature's ability of adaptive response to fluctuating environmental conditions. Specifically, the design of masonry building envelope systems is based on the structure of the barrel cactus, and the thermodynamic design of termite mounds.
\end{abstract}

Keywords: ceramic wall system, arid climate, barrel cacti, termites, passive systems, thermal control, radiation control.

\section{Introduction}

The American Southwest is a fragile ecosystem with finite energy and water resources. It is also the region of the United States experiencing the highest rate of population growth. Homes built to meet this demand rely on tightly constructed, highly insulated envelopes to lower energy consumption. Air conditioning using evaporators, condensers and compressors as the primary mode of thermal control, further strains the coal powered energy grid. In order to implement design strategies for building envelopes that rely on a direct relationship with the environment, our team studied the passive and active thermal control systems of barrel cacti and termite mounds. These natural systems have a direct relationship to their surroundings. The built environment can benefit from the continual tuning of passive systems to environmental conditions. 


\subsection{Case studies}

The thermoregulation systems of barrel cacti and termite mounds offer models for climatically responsive building technology. Barrel cacti are desert succulents and have one of the highest thermal tolerances of all plants and regulate their core temperature despite high diurnal temperature fluctuations [1]. Core temperature remains $2 / 3$ of the external skin temperature and stays within the ranges of $28-37^{\circ} \mathrm{C}\left(82-98^{\circ} \mathrm{F}\right)$ in summer and $16-18^{\circ} \mathrm{C}\left(60-64^{\circ} \mathrm{F}\right)$ in winter [2]. The barrel cactus stores water and operates as a living cistern. Water storage capacity allows survival during periods of extreme drought. Water delivers nutrients to the cacti, and serves as a heat sink, absorbing and distributing thermal load. Termites found in Côte d'Ivoire (Ivory Coast) thrive in both hot/arid and hot/humid climates. The design of the termite mound coupled with termite activity result in a symbiotic system that regulates the core temperature within $4^{\circ} \mathrm{C}\left(7.6^{\circ} \mathrm{F}\right)[3]$.

\subsection{Barrel cacti (Ferocactus wislizenii)}

A common architectural design strategy to moderate thermal gains is to reduce the ratio of building envelope to interior space. Conversely, barrel cacti integrate a layered system consisting of self-shading spines, a high surface area to circumference ratio, and liquid thermal mass to flourish during the high diurnal temperature swings and seasonal variations of the Sonoran region. Deep relief ribs, the undulated outer surface, are a distinguishing characteristic of barrel cacti, fig. 1, and contribute to the thermal performance of the system. Cacti ribs can increase the surface area up to $80 \%$ compared to a smooth cylinder of the same stem radius and shades greater than $60 \%$ of the cacti surface [2]. Ribs also serve as a high mass radiator, thermal collector and self-shading mechanism. Shaded surfaces reduce the absorbed shortwave solar radiation resulting in a slower warming period throughout the day. Convective heat transfer rate from the cacti to the environment is also reduced, figures $2-4$. Deep ribs reduce wind speeds generating an insulating air layer over the entire surface [2]. While the ribs hinder convective thermal loss during the day, they help retain heat during the cool desert nights and mitigate thermal transfer of heat from the skin to the stem. High surface area to circumference ratio results in lower net shortwave solar irradiation absorption and a moderated thermal transfer [2].
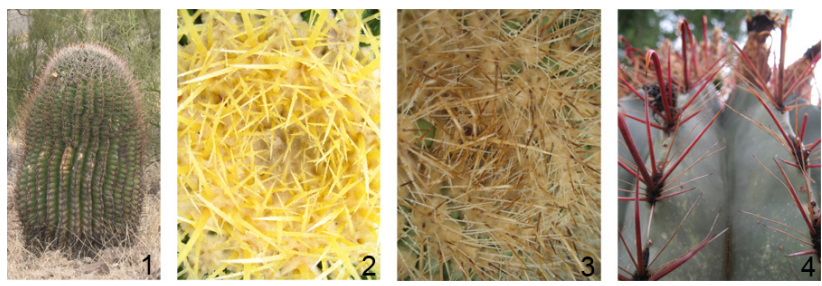

Figure 1: Barrel cactus. 1: barrel cacti. 2: yellow spines at the apex. 3: seasonal color change of the apex spines. 4: ribs and red to black spines near base. 

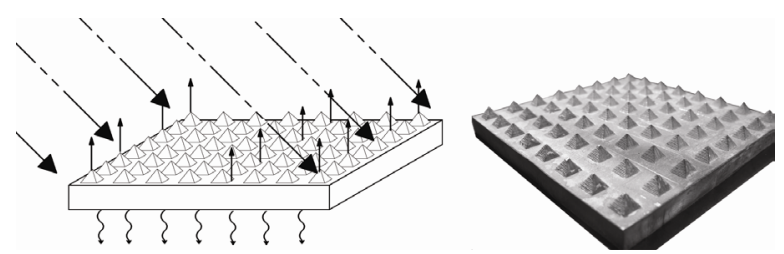

Figure 2: Aluminium (6061) tile with octahedral surface articulations. A heat lamp was placed such that the entire surface received radiant heat gain. Tile size, $4 " \mathrm{x} 4$ ".
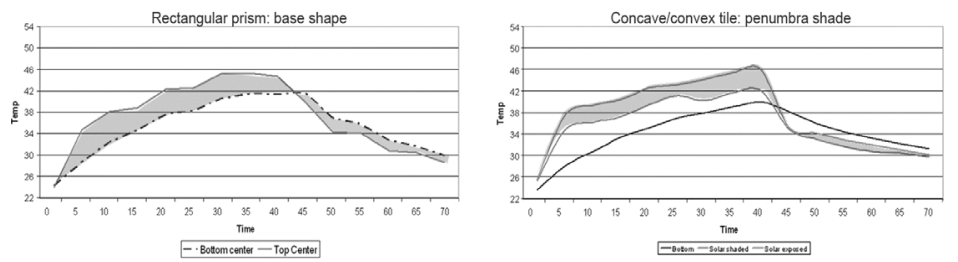

Figure 3: Thermal tests. On the left is a thermal transfer through a simple aluminium rectangular prism $\left(4^{\prime \prime} \times 4^{\prime \prime}\right)$. The experiment demonstrates a typical thermal exchange with solar radiation. The sun heats the exterior surface and is transferred by conduction to the interior, warming the inside face. On the right is the same mass of aluminium $5^{3}$ inches testing penumbra shade, concave and convex surface topography.
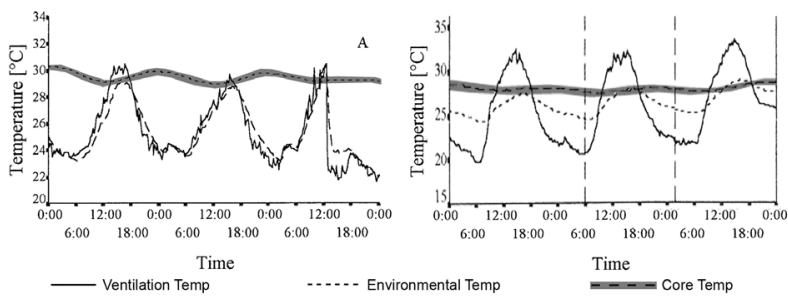

Figure 4: Thermal tests. The left graph shows thermal transfer through a rectangular prism with octahedral pyramids fig 2 . The experiment demonstrates that while increased surface area does obtain higher temperatures, the internal surface temperature remains much lower. The right is the same tile with the smooth surface towards the radiation source. The internal temperature is much higher than if the tool path is facing the radiation source, or if it were a plain rectangular prism.

In addition to the ribs, cacti spines minimize the thermal gains through color, concentration, and density of spine tissue. From May through September the spines at the apex of the cacti are yellow, fig. 1. Yellow spines effectively reflect 
solar irradiation [4]. After the most intense solar periods the apex becomes darker, absorbing solar radiation. On the trunk, the spines are dark red, fig. 1. and at the trunk base the spines vary in color from gray to black. The color gradient from yellow to black reflects the cacti's need for reflection or absorption of radiant thermal loads.

The second significant thermal characteristic of spines is density and location. The highest density occurs at the apex and the lowest density at the base of the cacti's trunk. Density increases the shading potential and controls convection across the surface. At the apex the spines form a thick mesh effectively eliminating convective thermal transfer. The trunk base has a relatively low concentration of spines and wider spacing of the ribs permitting limited convection transfer to the surrounding environment [5]. The third thermodynamic aspect of the spines is conduction via the density of the spine tissue. At the apex new tissue growth is soft with a waxy cuticle enabling the spine and cacti tissue to quickly release heat back to the environment. The trunk base is populated with dense grey and black spines having greater mass and thermal retention properties than those at the apex.

The cuticle of the cacti is a $2 \mathrm{~mm}$ in depth and insulates the cacti's stem. The inner cortex stores and transfers liquid. This massive layer has a density and thermal capacity similar to water, and absorbs and distributes thermal gain across the periphery of the cactus reducing thermal transfer to the core. The cactus also exchanges heat with the earth. Although the mode of thermal exchange is not well known, there is documentation of the earth immediately beneath the cacti heating at a greater rate than the typical desert floor [6].

\subsection{Termites (Macrotermes bellicosus)}

Termites in Côte d'Ivoire require a regulated environment of $30^{\circ} \mathrm{C}\left(86^{\circ} \mathrm{F}\right)$ and $80 \%$ humidity to thrive [3]. Termites are incapable of regulating their internal temperature so the insect resorts to the built environment, cathedral or dome mounds, as the primary climate control device. The termite adapted two prototypical mound designs to survive in both the arid savannah and the humid gallery forest.

Savanna, or cathedral mounds, experience both hot/arid and hot/humid seasons with high solar exposure year around [7]. Similar to barrel cacti, cathedral mound responds to shortwave solar irradiation as the primary means of reducing thermal gains. Orientation to a north/south axis reduces the duration of solar exposure during the most intense periods. Cathedral mound have a highly irregular surface topography that includes ridges, fig. 5, bumps and dimples that effectively double surface area [8]. The surface topography holds air, creating an insulating layer that reduces convection between the mound and the environment.

The cathedral mounds are designed to facilitate convective cooling [9]. During the day the mounds draw warm air down through a central chimney into the core. The air is then pulled up through the periphery in a ventilation network evacuating the heated air fig. 6. At night the process is reversed. Cool air is pulled down the warm periphery channels to first heat the core then move up the 

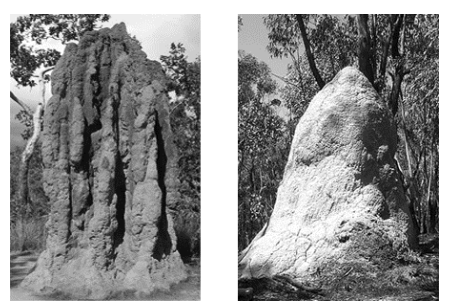

Figure 5: Typical termite mounds of Ivory Coast. Left, an example of the savannah termite mound, right, a typical design of a forest termite mound.

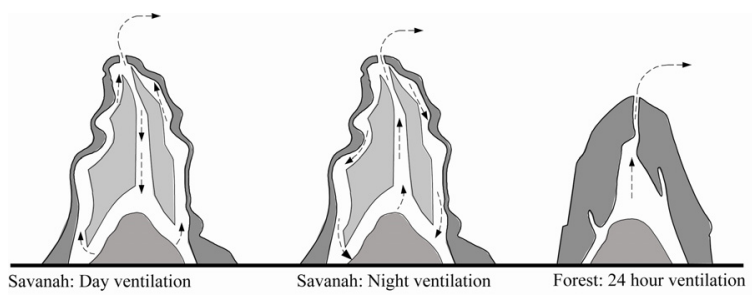

Figure 6: Ventilation diagram of termite mounds.

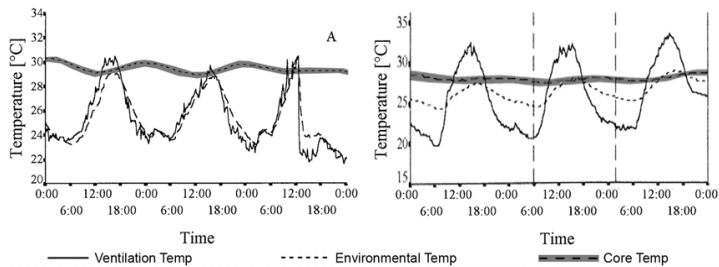

Figure 7: Core and environmental temperatures of termite mounds [7]. Termite mounds: left, cathedral mounds, right, dome mounds. The graph shows core temperatures compared to both environmental temperature swings and ventilation temperature swings over a consecutive three day period.

central chimney into the night [10]. Using these strategies the cathedral mounds can regulate the target core temperature to within $+/-2^{\circ} \mathrm{C}$, fig. 7 .

In the gallery forest, the canopy negates radiant heating as the primary thermal gain. Environmental loads, such as convection is the greatest threat to thermal regulation. Termites in the forest have an alternate strategy, fig. 5. To combat convection dome mounds are constructed with high exterior thermal mass and minimized surface area [8]. While a cathedral mound may have a wall thickness $1-5 \mathrm{~cm}$, dome mounds are 10-20 cm thick [8]. A thicker wall, coupled with reduced ventilation regulates the core temperature to $28^{\circ} \mathrm{C}\left(82.4^{\circ} \mathrm{F}\right)$ [10]. 
Accordingly, insulation, mass, and reduction of the envelope to interior space become important design strategies when radiation is not a primary factor.

Termites continue to adapt the mound in response to environmental changes. If shade is eliminated over the dome mounds, the termites alter their mounds to a cathedral design [10], resulting in a reduction in wall thickness, and an increase in surface articulation to match the solar exposure $[10,11]$. On the other hand, if a cathedral mound receives permanent shade, the termites resort to dome architecture. Mounds that fail to adapt, die. Termite mounds are constructed primarily from clay, silt and sand, which assist in regulating temperature and humidity in both designs by absorbing or releasing humidity throughout the year $[8,10]$.

\section{Discussion}

Both cacti and termite respond to solar radiation as the primary thermal gain, and secondly to convective thermal gain. In southern Arizona clouds shield the desert from radiation $15 \%$ of the year [12]. During the rest of the year a building must accommodate solar radiation as the primary thermal gain. As termites construct their mounds in response to radiation and convection, we, as designers, can develop high performance masonry units that are responsive to climatic fluctuations. The following project uses lessons of the case studies to thermal performance masonry wall system, fig. 8 .
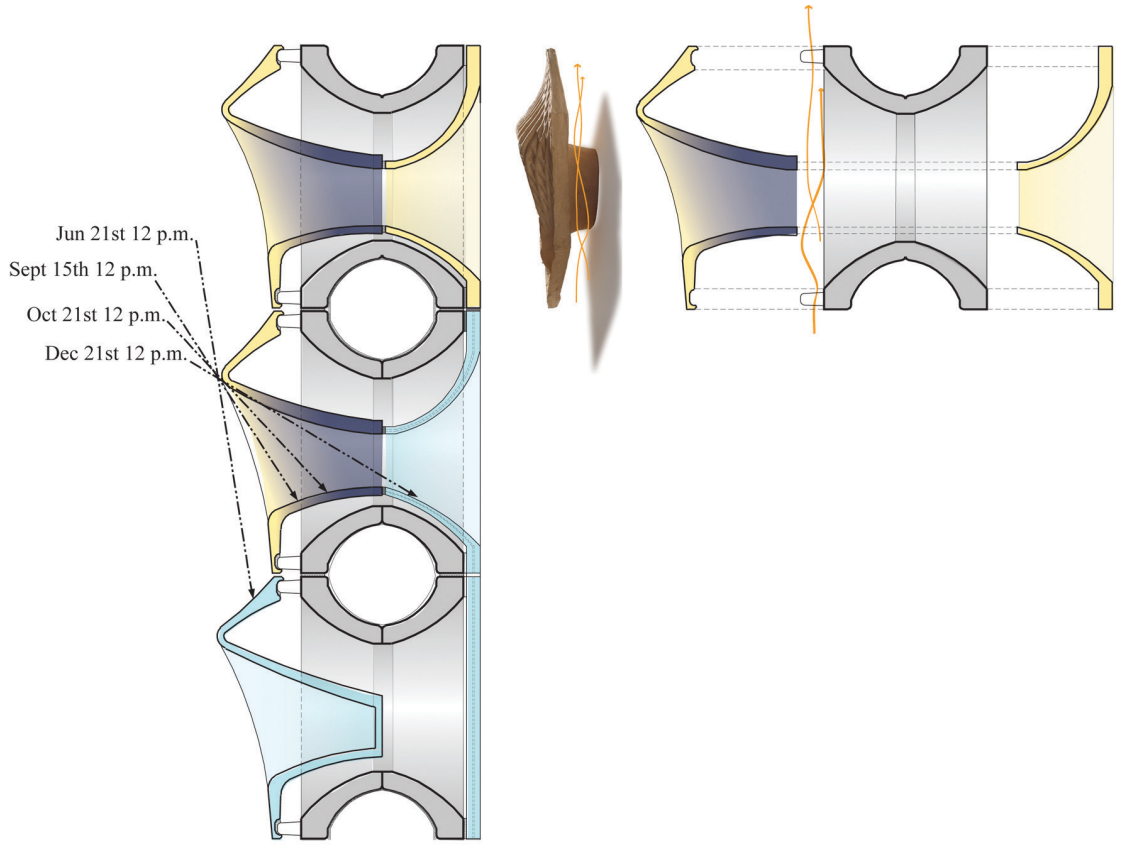

Figure 8: Wall system diagram, with notes on solar angles and surface textures. 


\subsection{Radiation}

The masonry wall system fig 8,9 has an articulated surface to provide summer shade and allows winter solar thermal gain. Demonstrated in figure 3 , the penumbra shaded region maintains a $4^{\circ} \mathrm{C}\left(\sim 7^{\circ} \mathrm{F}\right)$ thermal difference compared with a surface directly exposed to solar radiation. Even with $50 \%$ shading the interior temperature can still flux similarly to a non-shaded system $24-42^{\circ} \mathrm{C}(75-$ $108^{\circ} \mathrm{F}$ ), fig. 3. Rather than maintain cooler interior temperatures, shade delays the heating cycle fig. 3, 4. Although the gains may seem small, during the daylight hours from April through October it is advantageous to integrate a selfshading envelope.

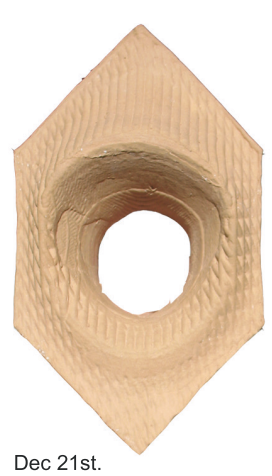

Feb/Oct 21st

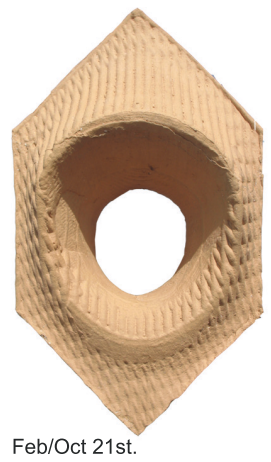

Apr/Aug 21st
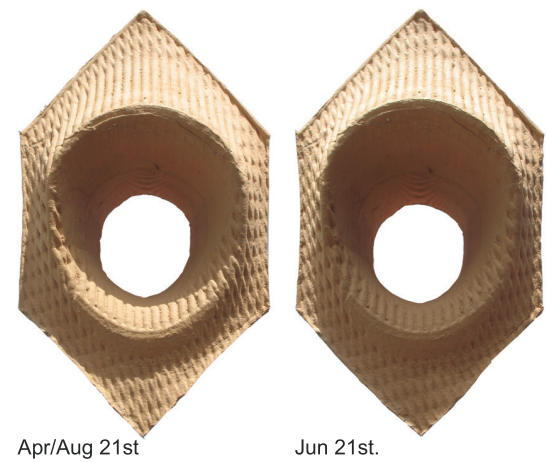

Figure 9: $\quad$ Prototype of face tile. Over the course of the year the face tile either shades itself or receives full sun. This enables us to tune the geometry of the face tile to a specific location for the heating and cooling months. From Arial to August the face is in 50\% shade reducing the radiant thermal gains, while from November to February face tile receives less than $10 \%$ shading enabling radiant heating of the wall.

Computer numerical control (CNC) surface articulations were milled into an aluminum plate, fig. 2. Thermal transfer on the milled surface was compared to a smooth plate. The surface with articulations releases heat and transfers less heat through the plate $\left(22-33^{\circ} \mathrm{C}, 71-91^{\circ} \mathrm{F}\right)$ than a penumbra shaded surface with no articulations fig. 3, 4. The smooth surface absorbs thermal loads, while the articulated surface releases thermal loads. To further increase effectiveness, two principles of shade and articulation will delay the heating cycle and releases heat.

In a second study a white and black glaze was applied to the tile to influence solar reflection, fig. 9, 10. During the most intense solar periods the white reflects up to $50 \%$ [13] of incoming radiation, while the winter the black absorbs up to $96 \%$ of incoming radiation [13]. The glaze also controls conduction, as the highly reflective white glaze draws heat from the tile and releases it to the atmosphere. 


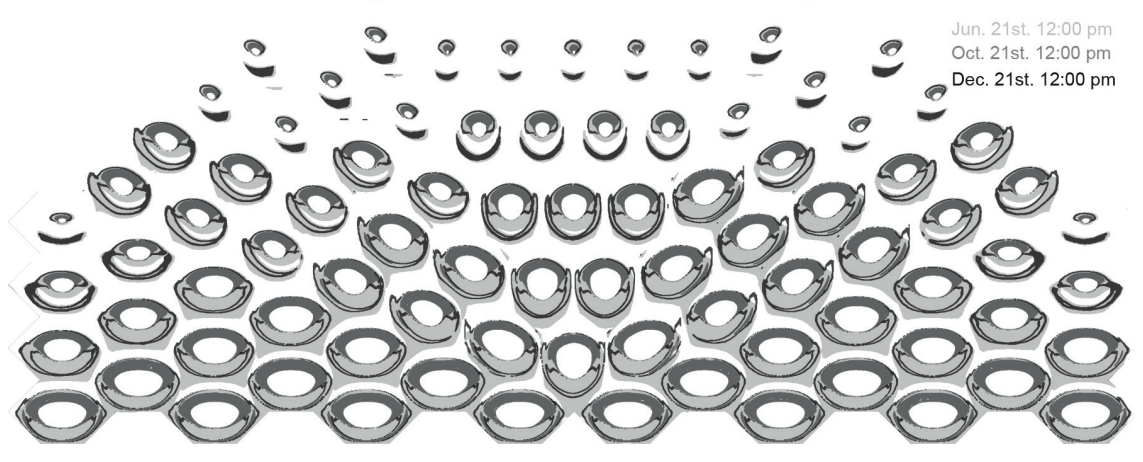

Figure 10: Diagram shows varying degrees of self-shading and targets where to apply black verses white glazing.

\subsection{Convection}

The wall system controls convection in two ways. Similar to the thermal regulation strategies of the termite mounds, the overall geometry of the face tile coupled with surface articulations generates a non-laminar air film moderating convection gain and loss. The second approach employs an interior ventilation strategy by separating the face tile from the structural brick, fig 8 , generating a laminar flow on the interior surface. Constant vertical air movement during from April to October evacuates the thermal load from the wall system.

Evaporative cooling is an effective means of tempering interior thermal conditions in arid regions and decreases the overall energy demand from air conditioning. The masonry wall system uses the evaporative cooling effect as the under fired ceramic will absorb water. For example, on a $38^{\circ} \mathrm{C}\left(100^{\circ} \mathrm{F}\right)$ day, with $15-35 \%$ relative humidity $(\mathrm{RH})$, evaporative cooling will lower the wall surface temperature and immediate surrounding air temperatures by $8-14^{\circ} \mathrm{C}\left(14-25^{\circ} \mathrm{F}\right)$ [14]. When RH rises above 50\%, evaporative cooling becomes ineffective. In southern Arizona the RH consistently remains at levels below $40 \%$ during daylight hours most of the year [12].

\subsection{Conduction}

The wall system uses thin tiles varying from $1-3 \mathrm{~cm}$ in thickness depending on location. Similar to the cathedral mounds, tile portions exposed to summer sun are thin, $1 \mathrm{~cm}$, enabling the masonry to absorb and release heat quickly. In the dome mounds, the tile's cone is thicker and serves as a heat sink, fig. 8, 9.

\subsection{Layers of control}

Combining the systems of form, surface geometry, glazing, ventilation, and evaporative cooling, the proposed masonry envelope system is capable of maintaining consistent interior temperatures, fig. 11. Initial testing indicates that surface geometry coupled with self-shading draws heat from an interior space 
fig. 4. Accordingly, both interior and the external thermal gains can be controlled through surface geometry.

Utilizing thermoregulation systems found in nature we can lower our dependence on fossil fuels. By designing intelligently and building loosely, we will increase our sensorial and cerebral connection with nature. We propose buildings that breathe, and when climatically appropriate, open to their surroundings, forming a healthier environment that increases the inhabitant's quality of life.

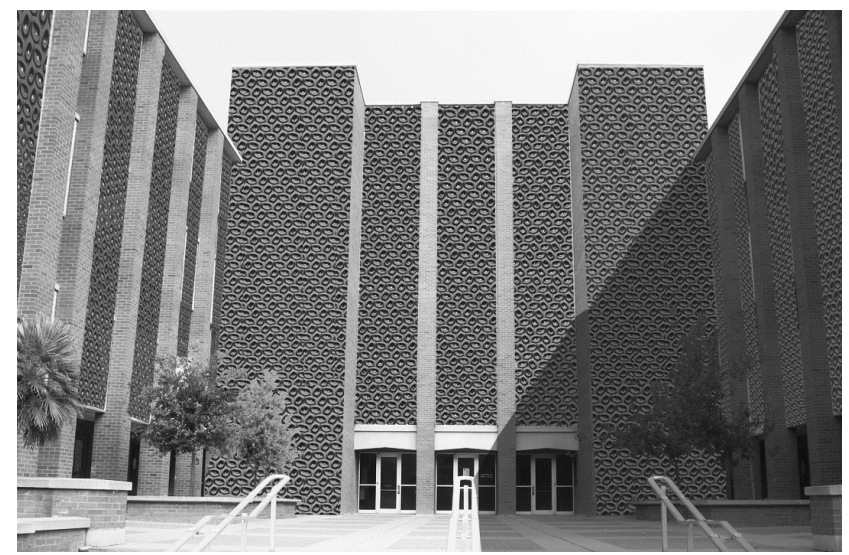

Figure 11: Application of masonry wall system to an existing building.

\section{References}

[1] Smith, Stanley D., \& Didden-Zopfy, Brigitte, \& Nobel, Park S. Hightemperature responses of North American cacti. Ecology., 65(2) pp. $643-$ 51, 1984.

[2] Lewis, D. A., \& Nobel, P. S. Thermal energy exchange model and water loss of a barrel cactus, ferocactus acanthodes. Plant Physiology., (60), pp. 609-16, 1977.

[3] Heinrich, B, and American Society of Zoologists. Insect thermoregulation. New York: Wiley, 1981.

[4] Watson, AN. Preliminary study of the relation between thermal emissivity and plant temperatures. Ohio Journal Science., 33, pp. 435-50, 1933.

[5] Nobel P. S., Water relations and photosynthesis of a barrel cactus, ferocactus acanthodes, in the Colorado Desert. Oecologia., 27, pp. 117-33, 1977.

[6] Gibbs JG, DT Patten. Plant temperatures and heat flux in a Sonoran desert Ecosystem. Oecologia., 5, pp. 65-84, 1970.

[7] Korb, J., and Linsenmair, K. E. Thermoregulation of termite mounds: what role does ambient temperature and metabolism of the colony play? Insectes Sociaux., 47(4), pp. 357-63, 2000. 
[8] Korb, J., and Linsenmair, K. E. The effects of temperature on the architecture and distribution of Macrotermes bellicosus (Isoptera, Macrotermitinae) mounds in different habitats of a West African Guinea savanna, Insectes Sociaux., 45, pp. 51-65, 1998.

[9] Seeley, T., \& Heinrich, B. Regulation of temperature in the nests of social insects. Journal of Comparative Physiology A: Neuroethology, Sensory, Neural \& Behavioral Physiology., 193(11) 159, 1981.

[10] Korb, J. Thermoregulation and ventilation of termite mounds. Naturwissenschaften., 90(5), pp. 212-19, 2003.

[11] Korb, J., and Linsenmair, K. E. Ventilation of termite mounds: new results require a new model. Behavior Ecology., 11(5), pp. 486-94, 2000.

[12] Comparative Climatic Data; U.S., National Climatic Data Center, NOAA, 2001. www.ncdc.noaa.gov/oa/climate

[13] Emissivity of Specific Materials; U.S., Cole Parmer, Website, Chicago IL. www.coleparmer.com

[14] Berman, A., Extending the Potential of Evaporative Cooling for Heat-Stress Relief. Journal of Dairy Science., 89, pp. 3817-3825, 2006. 